\title{
The Tetons
}

Interpretations of a Mountain Landscape 


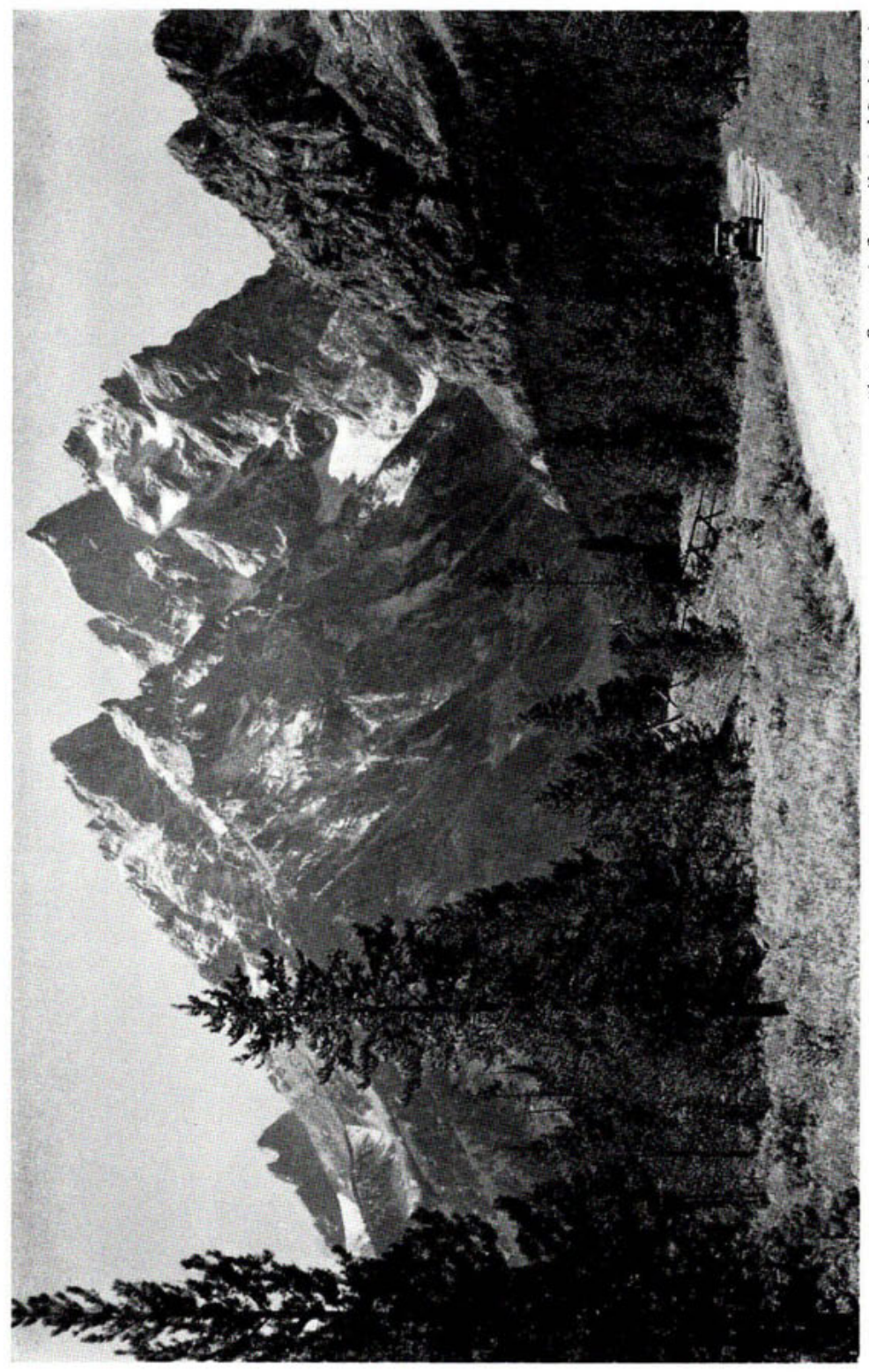

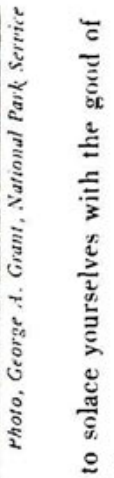

ڤั

今 苛产

ํㅗㅇ

$\rightarrow$ 욘

․․ㄴ

등 :

空 莺

되든

- 9

$\frac{5}{3} \frac{0}{3}$

$\pi$

는

는

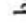

吾

छ

ธี

焉 


\section{THE}

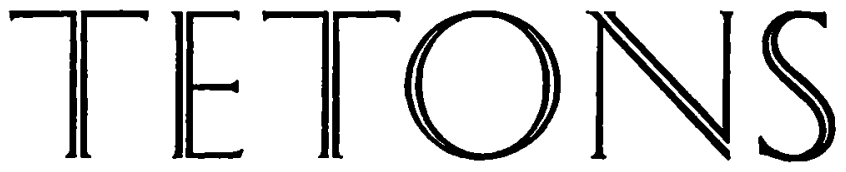

Interpretations of a Mountain Landscape By FRITIOF FRYXELL

\section{UNIVERSITY OF CALIFORNIA PRESS}

Berkeley and Los Angeles 1966 


\section{University of California Press \\ Berkeley and Los Angeles \\ California}

\section{Cambridge University Press \\ London, England}

Copyright, 1938, by

The Regents of the University of California

Copyright renewed, 1966,

by Fritiof Fryxell

Second printing, 1946

Third printing, 1953

Fourth printing, 1959

Fifth printing, 1966

Printed in the United States of America

by the University of California Press 
To R.H.F. 
